BRIEF REPORT

\title{
EVALUATION OF AN EDUCATIONAL PROGRAM FOR PRIMARY CARE PRACTITIONERS, ON THE MANAGEMENT OF OSTEOARTHRITIS
}

\author{
JEOFFREY K. STROSS and GILES G. BOLE
}

The quality of health care depends, in part, on the rapidity with which health professionals are willing to adapt to medical innovation and adjust patient care practices in light of new knowledge. By understanding how information is transmitted and under what conditions physicians will accept innovation, we can design educational programs that have a high probability of changing physician behavior.

Primary care physicians practicing in community settings often rely on informal and personal methods of education. Actual experiences in patient care are probably the strongest influences that bring about changes in professional practice. When faced with clinical problems, primary care practitioners commonly turn to colleagues for advice. Previous studies have demonstrated the presence of key individuals in each community who are consulted frequently. These practitioners, referred to as "educationally influential physicians" or EIs, have the ability to change their peers' behavior in a desired manner (1).

This project was based on the hypothesis that Arbor

From the University of Michigan Medical School, Ann

Supported by Multipurpose Arthritis Center grant $2 \mathrm{P} 60$ AM20557 from the National Institute of Arthritis, Diabetes, Digestive and Kidney Diseases.

Jeoffrey K. Stross, MD: Associate Professor of Internal Medicine and Director, Community Programs Component, University of Michigan Arthritis Center; Giles G. Bole, MD: Professor of Internal Medicine, Director, University of Michigan Arthritis Center, and Physician-in-Charge, Division of Rheumatology, University of Michigan Medical School.

Address reprint requests to Dr. I. Stross, D3211 South Ambulatory Care Building, The University of Michigan Medical Center, Ann Arbor, MI 48109.

Submitted for publication March 6, 1984; accepted in revised form July $9,1984$.
EIs can be used to disseminate information to their colleagues about the management of osteoarthritis (OA). Osteoarthritis is the most common disease in humans, with radiologic evidence of the disease found in more than $80 \%$ of people over the age of $55(2)$. The prevalence rises rapidly with age, with as many as $10 \%$ of the population already having radiographic findings by age 25 (3). Over 40 million Americans have radiologically visible $O A$ in the hands or feet, and symptoms of disability have occurred in 5 million (4).

Many physicians have developed pessimistic attitudes about OA because of its frequent downhill course with increasing joint dysfunction and lack of effective treatment. This may not be warranted, because of our growing knowledge about the pathogenesis of the disease process, new treatment approaches, and advances in joint replacement. Since primary care physicians treat most patients with rheumatic diseases, we developed an educational program for these practitioners, on the management of OA. This program was delivered to a small group of physicians identified by their peers as EIs, who then had the responsibility of disseminating the information to their peers. Instructional objectives were defined, a needs assessment carried out, and the educational program was developed. The educational program was selfstudy in design, utilizing a syllabus and audiovisual aids to minimize faculty teaching time. This report describes the project and our efforts to assess the impact of the educational program on the target population.

Methods. The first step was to identify the project communities. All communities in the state of Michigan were surveyed for the following characteristics: no physician with formal training in rheumatol- 
ogy, no ongoing medical educational programs (undergraduate or graduate), at least 15 primary care practitioners in the area, a location at least 25 miles from a referral center, an orthopedic surgeon practicing in the community, and a physical therapy unit in operation at the hospital. Letters were sent to all communities with these characteristics, and 6 communities agreed to participate. Three were randomly selected to be controls, while the other 3 were designated as intervention communities. The EIs were selected using a previously described method (1), and the individual identified in each community was recruited into the project.

The next step was to develop the educational program. Three tasks were identified: defining the instructional goals, performing a needs assessment for the learner group, and developing the instructional materials.

The instructional goals were defined by a group of primary care physicians and rheumatologists. They met to determine what knowledge and skills primary care practitioners should have in order to adequately care for patients with OA. There were 3 major categories identified: diagnosis, management, and referral and education. For each category, instructional objectives relating to knowledge and skills were specified; these are outlined in Table 1. Differences between physicians were minor and were resolved by discussion. No major areas of disagreement were identified, and there was widespread consensus at the end of the session.

After defining the educational objectives, it was necessary to assess the knowledge and skill levels of the EIs and to document the actual practices of primary care physicians in the management of OA. The EIs were asked to complete a written examination prior to the educational program. The questions were derived from the instructional objectives, and 2 questions were developed for each point: 1 for the pre-test and the other for the post-test. The questions were in true/false, multiple choice, or matching format.

The needs assessment included chart audits of all inpatients with a discharge diagnosis of OA. Physical therapy records were reviewed to identify patients not picked up by other methods, and all patients undergoing total hip arthroplasty (THA) for OA were also reviewed. All records were audited against predefined criteria, as were outpatient records in most instances. Data on each patient's history, physical examination, laboratory studies, management, and disposition were collected.
Table 1. Instructional objectives of "educationally influential" physician intervention

I. Diagnosis of osteoarthritis

A. Knowledge-the learner group, at the completion of the program, must be able to:

1. Discuss the pathophysiology of osteoarthritis.

2. Describe the prevalence of osteoarthritis.

3. Differentiate osteoarthritis from other forms of joint disease.

B. Skills-the learner group must be able to:

1. Elicit a history documenting the cardinal features of joint disease.

2. Perform and record the findings of a joint examination.

3. Order and interpret laboratory and radiographic studies in patients with osteoarthritis.

II. Management of osteoarthritis

A. Knowledge-the learner group must be able to describe:

1. The pharmacology of nonsteroidal antiinflammatory agents.

2. A comprehensive program for the management of osteoarthritis.

B. Skills-the learner group must be able to:

1. Prescribe full-dose aspirin therapy.

2. Prescribe nonsteroidal antiinflammatory agents.

3. Instruct a patient in a comprehensive program of management of osteoarthritis.

4. Perform and interpret an arthrocentesis.

III. Referral and education of patients with osteoarthritis

A. Knowledge-the learner group must be able to:

1. Understand the rationale for physical therapy for osteoarthritis.

2. State the indications for referral for surgical intervention in osteoarthritis.

B. Skills-the learner group must be able to:

1. Refer patients to physical therapists and orthopedic surgeons as indicated.

The last step in the development of the educational program was selection of the educational materials. Although this program could be utilized by any physician, it was aimed at a specific group of practitioners identified as EIs. Since these individuals are very busy, a decision was made to develop a self-study program. The 3 components of this program included a basic textbook to serve as a reference source, a syllabus of recent articles, and audiovisual materials. After completion of the pre-test, the educational materials were sent out to each participant, with the areas necessitating further study being highlighted. A posttest was sent 2 months later, after each participant completed the program.

One year after completion of the educational program, the medical records were reaudited using the same criteria. Statistical comparisons were made using chi-square. 
Table 2. Pre-program inpatient audit results*

\begin{tabular}{|c|c|c|}
\hline Variable & $\begin{array}{l}\text { Control } \\
\text { hospitals } \\
(n=44)\end{array}$ & $\begin{array}{c}\text { Intervention } \\
\text { hospitals } \\
(\mathrm{n}=41)\end{array}$ \\
\hline \multicolumn{3}{|l|}{ Diagnosis } \\
\hline Osteoarthritis & 18 & 23 \\
\hline Total hip arthroplasty & 26 & 18 \\
\hline \multicolumn{3}{|l|}{ Length of stay (days) } \\
\hline Osteoarthritis & 8.4 & 8.8 \\
\hline Total hip arthroplasty & 16.6 & 17.2 \\
\hline \multicolumn{3}{|l|}{ Therapy (osteoarthritis) } \\
\hline Aspirin & $9(50)$ & $9(39)$ \\
\hline $\begin{array}{l}\text { Nonsteroidal antiinflammatory } \\
\text { agents }\end{array}$ & $14(78)$ & $19(83)$ \\
\hline Corticosteroids (systemic) & $3(17)$ & $3(13)$ \\
\hline Corticosteroids (intraarticular) & $2(11)$ & $4(17)$ \\
\hline Physical therapy & $15(83)$ & $20(87)$ \\
\hline Referral & $7(39)$ & $9(39)$ \\
\hline \multicolumn{3}{|l|}{ Therapy (total hip arthroplasty) } \\
\hline Pre-op length of stay (days) & 1.5 & 2.2 \\
\hline Pre-op physical therapy & $12(46)$ & $10(56)$ \\
\hline Post-op narcotics & $20(77)$ & $13(72)$ \\
\hline Post-op physical therapy & $26(100)$ & $18(100)$ \\
\hline Post-op complications & $4(15)$ & $2(11)$ \\
\hline
\end{tabular}

* Numbers in parentheses are percentages.

Results. The average score for the 3 physicians in the pre-test was $58.2 \%$; this improved to $84.1 \%$ in the post-test. As a result of this improvement, we felt confident that the participating physicians had the requisite knowledge to disseminate to their peers.

In the pre-intervention period, 85 patients were discharged from the 6 hospitals with a primary discharge diagnosis of OA: 44 in the control and 41 in the intervention hospitals. The male/female distribution and average ages of the patients were similar in the 2 groups. Forty-four of the patients $(52 \%)$ underwent THA (Table 2). The length of stay and nonoperative management of patients with OA were similar in the control and intervention communities. There were no obvious differences in the management of the THA patients in the 2 groups. A total of 436 outpatient charts were audited: $230(52.8 \%)$ in the control communities and $206(47.2 \%)$ in the intervention communities. There were no significant differences in the therapy received by these groups. Nonsteroidal antiinflammatory agents were the main therapy used (86\%), while systemic corticosteroids were rarely used $(9 \%)$, and intraarticular corticosteroids were given to $15 \%$ of outpatients. Physical therapy was recommended in $45 \%$ of outpatients, and referral to an orthopedic surgeon or rheumatologist was noted in $18 \%$.

In the post-intervention period, $114 \mathrm{OA}$ patients were discharged from the 6 hospitals: 48 in the control and 66 in the intervention communities (Table 3). The increased number of patients in the intervention communities was seen in operative as well as medically managed cases. While the length of stay was unchanged in THA patients at the control hospitals, there was a 2.0-day reduction in the length of stay of those patients at the intervention hospitals. The only significant changes in therapy for the medically managed patients were increased utilization of intraarticular corticosteroids and decreased use of systemic corticosteroids. In those patients undergoing THA, there was a significant increase in utilization of physical therapy services in the preoperative period, a key point in the educational program. No other significant differences from the pre-intervention period were noted postintervention. A total of 472 outpatient charts were audited in the post-intervention period: $238(50.4 \%)$ in the control and $234(49.6 \%)$ in the intervention communities. There were no significant changes from the pre-intervention period in the use of systemic medications, physical therapy, or specialty referral. The use of intraarticular corticosteroids increased in the intervention communities from 30 of 206 outpatients $(14.6 \%)$ to 56 of $234(23.9 \%)(P<0.05)$, while similar changes were not seen in the control communities.

Discussion. Since rheumatologists treat only a small percentage of patients with rheumatic diseases, it is increasingly important to target our educational efforts toward primary care physicians. These individ-

Table 3. Post-program inpatient audit results*

\begin{tabular}{|c|c|c|}
\hline Variable & $\begin{array}{r}\text { Control } \\
\text { hospitals } \\
(n=48)\end{array}$ & $\begin{array}{l}\text { Intervention } \\
\text { hospitals } \\
(\mathrm{n}=66)\end{array}$ \\
\hline \multicolumn{3}{|l|}{ Diagnosis } \\
\hline Osteoarthritis & 18 & 30 \\
\hline Total hip arthroplasty & 30 & 36 \\
\hline \multicolumn{3}{|l|}{ Length of stay (days) } \\
\hline Osteoarthritis & 8.6 & 8.4 \\
\hline Total hip arthroplasty & 16.0 & 15.2 \\
\hline \multicolumn{3}{|l|}{ Therapy (osteoarthritis) } \\
\hline Aspirin & $5(28)$ & $6(20)$ \\
\hline $\begin{array}{l}\text { Nonsteroidal antiinflammatory } \\
\text { agents }\end{array}$ & $17(94)$ & $26(87)$ \\
\hline Corticosteroids (systemic) & $4(22)$ & $1(3) \dagger$ \\
\hline Corticosteroids (intraarticular) & $2(11)$ & $12(40) \dagger$ \\
\hline Physical therapy & $15(83)$ & $28(93)$ \\
\hline Referral & $6(33)$ & $9(30)$ \\
\hline \multicolumn{3}{|l|}{ Therapy (total hip arthroplasty) } \\
\hline Pre-op length of stay (days) & 1.3 & 1.6 \\
\hline Pre-op physical therapy & $12(40)$ & $35(97) \dagger$ \\
\hline Post-op narcotics & $28(93)$ & $32(89)$ \\
\hline Post-op physical therapy & $30(100)$ & $36(100)$ \\
\hline Post-op complications & $4(13)$ & $2(6)$ \\
\hline
\end{tabular}

* Numbers in parentheses are percentages.

$\dagger P<0.05$ versus pre-intervention. 
uals often rely on informal methods of communication, so we designed a program to capitalize on this method of information dissemination. A group of physicians, identified by their peers as being educationally influential, were provided with additional knowledge about OA. We then attempted to determine what impact these individuals would have on the behavior of their peers.

While there have not been any dramatic breakthroughs in the management of $\mathrm{OA}$ in the past few years, some advances have been made. The preprogram audit demonstrated that nonsteroidal antiinflammatory agents and physical therapy already played an important role in patient management. Our educational efforts were concentrated on 3 therapeutic modalities: the use of intraarticular corticosteroids, the role of physical therapy, and joint replacement.

The post-program audit documents that some changes in behavior occurred. While there were minimal changes in activity in the control hospitals, there was a $60 \%$ increase in hospitalizations in the intervention communities, with a doubling of admissions for THA. The indications for THA were examined in each case, and 33 of 36 in the intervention hospitals (92\%) were performed because of pain that was unresponsive to a conservative program of pain medication and physical therapy. This suggests that this increase in activity was clinically justified. There was a significant increase in the use of intraarticular corticosteroids in both inpatient and outpatient settings in the intervention communities. It could be argued that this modality may not be clinically indicated, but important diagnostic information can be obtained at the time of arthrocentesis, and intraarticular corticosteroids can provide temporary symptomatic relief.

The major impact of this project was to inform primary care practitioners of the value of joint replacement. The number of procedures doubled in the intervention hospitals, the length of stay decreased by $\mathbf{2 . 0}$ days, and preoperative physical therapy was routinely instituted. Since these changes were not seen in the control hospitals and were key features of the educational program, a cause-and-effect relationship is suggested.

One major difference in this project compared with our previous programs using educationally influential physicians was the use of a self-study educational program. In previous studies, we utilized an intensive, academic medical center-based preceptorship. While this approach was successful, it was highly dependent upon scarce resources: an academic center and many hours of faculty time. Consequently, we used a different format in the current study. The change in knowledge was impressive, and the change in behavior of the community practitioners is similar to what has been seen previously (5). These changes are not as dramatically impressive as those seen when a new rheumatologist enters practice (6), but it is very doubtful that there will ever be an adequate supply of rheumatologists to go to communities with populations of less than 25,000 .

These data confirm our previous findings concerning the role of EIs in disseminating information to their peers and in influencing their behavior. In those less-populated areas where subspecialty-oriented physicians are unlikely to establish a practice, this approach to educating primary care physicians has utility and value.

\section{REFERENCES}

1. Stross JK, Hiss RG, Watts CM, Davis WK, MacDonald $\mathrm{R}$ : Continuing education in pulmonary disease for primary care physicians. Am Rev Respir Dis 127:739-746, 1983

2. Kellgren JH, Lawrence JS: Osteoarthrosis and disc degeneration in an urban population. Ann Rheum Dis 17:388-397, 1958

3. Lawrence JS, Bremner JM, Bier F: Osteoarthrosis prevalence in the population and relationship between symptoms and x-ray changes. Ann Rheum Dis 25:1-24, 1966

4. Gordon T: Osteoarthrosis in US adults, Population Studies of the Rheumatic Diseases. Edited by PH Bennett, PHN Wood. New York, Excerpta Medica Foundation, 1968, pp 391-397

5. Stross JK, Bole GG: Evaluation of a continuing education program in rheumatoid arthritis. Arthritis Rheum 23:846849,1980

6. Stross JK, Bole GG: The impact of a new rheumatologist on the management of rheumatic disease patients in community hospitals. Arthritis Rheum 26:1033-1036, 1983 